\title{
Desain Media Pembelajaran Berbentuk Permainan Ular Tangga Berbasis Penguasaan Konsep Siswa
}

\author{
Tarmidzi $^{1 *}$, Dian Permana Putri ${ }^{2}$, Abyan Zahran ${ }^{3}$ \\ 1,2,3Program Studi PGSD, Universitas Swadaya Gunung Jati, Cirebon, Indonesia \\ Email Korespondensi: *mulyatarmidzi@gmail.com
}

\begin{abstract}
Abstrak. Pembelajaran yang terjadi di kelas merupakan kegiatan yang sangat berpengaruh terhadap proses pendidikan. Guru harus memiliki kemampuan dalam mengemas rancangan pembelajaran yang baik diawali dengan persiapan yang matang. Salah satu cara untuk mengatasi masalah tersebut dengan melakukan kreativitas pada pelaksanaan pembelajaran, salah satunya dengan memanfaatkan media pembelajaran yang dapat merangsang siswa menjadi lebih aktif dan tidak gampang bosan saat pembelajaran berlangsung. Media pembelajaran adalah komponen-komponen sumber belajar yang mengandung materi-materi instruksional pada lingkungan siswa yang dapat merangsang siswa untuk belajar. Desain dan pengembangan media pembelajaran ini difokuskan pada materi sumber energi untuk siswa kelas IV sekolah dasar. Penelitian ini dilaksanakan menggunakan pendekatan kualitatif dengan menggunakan metode penelitian desain (Design Research) dengan langkah-langkah, diantaranya: 1) permasalahan; 2) analisis; 3) desain/perancangan; 4) evaluasi/validasi. Data penelitian dikumpulkan melalui wawancara sebagai analaisis kebutuhan dan angket untuk validasi media yang dikembangkan. Hasil penelitian menunjukkan ahwa media pembelajaran berbentuk permainan ular tangga yang dikembangkan sudah menarik dan valid sehingga layak untuk digunakan dalam pembalajaran di kelas.

Kata kunci: Media Pembelajaran, Permainan Ular Tangga, Penguasaan Konsep
\end{abstract}

\begin{abstract}
Learning that occurs in class is an activity that greatly influences the educational process. Teachers must have the ability to package a good learning design starting with careful preparation. One way to overcome this problem is by doing creativity in the implementation of learning, one of which is by using learning media that can stimulate students to be more active and not easily get bored when learning takes place. Learning media are components of learning resources that contain instructional materials in student environments that can stimulate students to learn. The design and development of this instructional media is focused on material sources of energy for fourth grade elementary school students. This research was conducted using a qualitative approach using the design research method (Design Research) with steps, including: 1) problem; 2) analysis; 3) design / design; 4) evaluation / validation. The research data was collected through interviews as a needs analysis and a questionnaire to validate the developed media. The results showed that the learning media in the form of a game of snakes and ladders that were developed were interesting and valid so that they were suitable for use in classroom learning.
\end{abstract}

Keywords: Learning Media, Snakes and Ladders Game, Concept Mastery

\section{Pendahuluan}

Pembelajaran yang terjadi di kelas merupakan kegiatan yang sangat berpengaruh terhadap proses pendidikan (Tyaningsih, 2012). Apabila pembelajaran di kelas dikemas secara baik dan menarik maka akan 
menghasilkan output yang berkualitas. Guru harus memiliki kemampuan dalam mengemas rancangan pembelajaran yang baik diawali dengan persiapan yang matang. Salah satu cara untuk mengatasi masalah tersebut dengan melakukan kreativitas pada pelaksanaan pembelajaran, salah satunya dengan memanfaatkan media pembelajaran yang dapat merangsang siswa menjadi lebih aktif dan tidak gampang bosan saat pembelajaran berlangsung. Untuk itu, keterampilan guru dalam menjaga dan meningkatkan motivasi belajar siswa sangat diperlukan, terlebih lagi dalam pembelajaran yang bersifat sosial akan sangat diperlukan sekali media pembelajaran yang menarik minat siswa dan memicu keinginan siswa untuk memahami isi materi yang dipelajari (Tafonao, 2018). Undangundang no.14 Tahun 2005 tentang guru dan dosen mengamanatkan guru untuk dapat memiliki kompetensi pedagogik dimana guru harus mampu menguasai proses pembelajaran, dalam artian guru menguasai strategi pembelajaran dan mampu membuat media pembelajaran yang inovatif sesuai kebutuhan dalam proses pembelajaran di kelas (Afandi, 2015).

Media pembelajaran adalah komponen-komponen sumber belajar yang mengandung materi-materi instruksional pada lingkungan siswa yang dapat merangsang siswa untuk belajar (Karimah, 2014:7). Diantara manfaat media pembelajaran adalah menjadikan pembelajaran lebih interaktif, menarik, dan mampu mengubah persepsi siswa tentang materi dan proses belajar menjadi lebih positif serta mampu mengubah peran guru menjadi lebih positif dan produktif (Rasyid \& Rohani 2018). Media pembelajaran sendiri dapat dibedakan menjadi a) media grafis; b) media audio; dan c) media proyeksi (Purwono, dkk 2014). Meskipun begitu, guru tetap harus memerhatikan kesesuaian media yang akan digunakan dengan karakteristik materi maupun siswa (Purwanti, 2015). Media pembelajaran yang dapat membuat siswa menjadi lebih aktif dan menyenangkan yaitu bermain sambil belajar. Permainan (games) adalah sebuah konteks antar pemain yang berinteraksi satu sama lain dengan mengikuti aturan-aturan tertentu untuk mencapai tujuan-tujuan tertentu pula (Salam, 2019).

Modal awal untuk pembinaan kecerdasan dan mental emosional dan intelektual anak adalah permainan saat anak bertukar pikiran pikiran melalui bahasa, melukis, membuat keputusan dan memecahkan masalah, dan saat merasakan perbedaan antara fantasi dan realitas (Nur, dkk., 2017). Selain itu, permainan yang memfasilitasi anak untuk menampilkan gagasan baru secara lancar dan orisinil mampu menciptakan kebebasan psikologis bagi anak (Ninik, 2018: 109). Manfaat permainan sendiri bagi kegiatan belajar salah satunya adalah memberi kesempatan kepada siswa untuk memahami, 
meresapi dan memberi arti sehingga membetnuk mindset siswa dari materi yang dipelajari (Kusumawati, 2017). Salah satu permainan yang dapat digunakan sebagai media pembelajaran adalah permainan ular tangga.

Permainan ular tangga merupakan permainan tradisional yang dimainkan oleh minimal dua orang dan sangat terkenal di nusantara (Feryka, 2017). Dalam penelitian ini, penulis memilih untuk mengembangkan media pembelajaran berupa permainan ular tangga berbasis penguasaan konsep. Hal ini didasari bahwa kurangnya penggunaan media yang bervariasi dalam pembelajaran di kelas, membuat siswa hanya mendengar dan menghafalkan saja, sehingga penguasaan konsep siswa menjadi rendah, padahal penguasaan konsep diperlukan agar siswa mampu mengembangkan suatu konsep yang telah diberikan secara teori maupun penerapannya dalam kehidupan sehari-hari dan membawa konsep tersebut dalam bentuk lain, tidak sama dengan yang ada di dalam buku teks (Arisanti, dkk, 2016:83-84).

Media pembelajaran yang akan dirancang diharapkan dapat membantu siswa, karena belajar dan bermain merupakan kegiatan yang tidak dapat dipisahkan dalam kehidupan anak usia sekolah dasar. Bermain memiliki peran terhadap perkembangan anak. Maka dari itu, melalui penggunaan media permainan ular tangga berbasis penguasaan konsep, selain siswa dapat bermain, siswa dapat pula belajar dengan menyenangkan, dan dapat dengan mudah berkomunikasi maupun menyampaikan informasi materi pembelajaran kepada siswa.

Desain dan pengembangan media pembelajaran ini difokuskan pada materi sumber energi untuk siswa kelas IV sekolah dasar. Langkah penelitian dimulai dengan wawancara terhadap guru kelas IV untuk mendapatkan informasi tentang pemanfaatan media dan pelaksanaan pembelajaran di kelas. Dari wawancara tersebut diharapkan didapat informasi tentang pemanfaatan media terutama yang berbasis penguasaan konsep. Setelah itu penulis akan melakukan desain dan pengembangan media pembelajaran untuk dapat dimanfaatkan dalam pembelajaran di sekolah dasar. Adapun penguasaan konsep yang digunakan dalam penelitian ini adalah penguasaan konsep dari Bloom yang telah disempurnakan oleh Anderson \& Krathwol. Penguasaan konsep sendiri merupakan kemampuan siswa dalam memahami konsep-konsep setelah kegiatan pembelajaran (Astuti, 2017). Berdasarkan hal tersebut, maka tujuan penelitian ini adalah untuk mengetahui desain produk permainan ular tangga berbasis penguasaan konsep siswa pada materi sumber energi dan kelayakannya untuk digunakan dalam pembelajaran di kelas. 


\section{Metode}

Penelitian ini dilaksanakan menggunakan pendekatan kualitatif dengan menggunakan metode penelitian desain (Design Research). Penelitian ini memiliki beberapa langkah, diantanya: 1) permasalahan; 2) analisis; 3) desain/perancangan; 4) evaluasi/validasi (Plomp, 2013). Subjek dalam penelitian ini adalah guru sekolah dasar di Kota Cirebon. Data dikumpulkan melalui beberapa teknik, diantaranya wawancara sebagai analisis kebutuhan (need aseesment) terhadap desain media ular tangga berbasis penguasaan konsep siswa pada materi sumber energi. Wawancara ini dilakukan untuk mendapatkan informasi mengenai kebutuhan guru mengenai media ular tangga berbasis penguasaan konsep. Instrumen wawancara dibagikan kepada guru agar dapat mengetahui kebutuhan mengenai peserta didik dalam pembelajaran, maupun terhadap peran media pembelajaran guna menunjang kesulitan dalam pembelajaran.

Data lainnya didapat melalui angket. Angket yang digunakan dalam penelitian ini dijadikan acuan dalam keberhasilan produk hasil penelitian. Angket yang diberikan berupa pertanyaan untuk menggali informasi tentang kelayakan media ular tangga, ketepatan isi, dan juga kemenarikan desain. Angket dibuat sebagai bahan validasi oleh validator sesuai dengan bidang keahlian masing-masing, seperti ahli materi dan ahli media. Analisis terhadap data hasil wawancara dan angket dilakukan secara deksriptif kualitatif.

\section{Hasil dan Pembahasan}

Angket wawancara diberikan kepada beberapa guru sekolah dasar di Kota Cirebon. Angket wawancara ini disebar untuk mengetahui respons guru terhadap penggunaan media pembelajaran yang telah dilaksanakan oleh guru selama ini. Hasil wawancara dapat ditampilkan pada Tabel 1.

Tabel 1. Hasil Wawancara Need Assesment

\begin{tabular}{|c|c|c|c|}
\hline No. & Pertanyaan & Jawaban & Persentase \\
\hline 1. & $\begin{array}{l}\text { Bagaimana guru melaksanakan } \\
\text { pembelajaran di kelas? }\end{array}$ & $\begin{array}{l}100 \% \text { menggunakan media } \\
\text { pembelajaran }\end{array}$ & $100 \%$ \\
\hline \multirow{2}{*}{2.} & \multirow{2}{*}{$\begin{array}{l}\text { Metode apa yang biasa digunakan } \\
\text { guru dalam pembelajaran kelas? }\end{array}$} & kerja kelompok/diskusi & $75 \%$ \\
\hline & & ceramah & $25 \%$ \\
\hline 3. & $\begin{array}{l}\text { Apakah peran media dalam } \\
\text { melaksanakan pembelajaran itu } \\
\text { penting? }\end{array}$ & merasa penting & $100 \%$ \\
\hline \multirow[t]{2}{*}{4.} & \multirow{2}{*}{$\begin{array}{l}\text { Bagaimana guru memanfaatkan } \\
\text { media dalam pembelajaran di kelas } \\
\text { terutama dalam materi IPA? }\end{array}$} & $\begin{array}{l}\text { tergantung materi yang } \\
\text { dipelajari }\end{array}$ & $75 \%$ \\
\hline & & selalu membuat media & $25 \%$ \\
\hline 5. & Media apakah yang dibutuhkan guru & membuat media yang & $100 \%$ \\
\hline
\end{tabular}

Caruban: Jurnal Ilmiah Pendidikan Dasar 4(1), 1-9, Januari 2021

DOI: http://dx.doi.org/10.33603/.v4i1.4811, p-ISSN 2615-1391, e-ISSN 2620-3219

CProdi PGSD, Universitas Swadaya Gunung Jati 


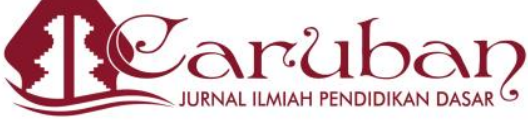

\begin{tabular}{|c|c|c|c|}
\hline No. & Pertanyaan & Jawaban & Persentase \\
\hline & $\begin{array}{l}\text { untuk membantu pelaksanaan } \\
\text { pembelajaran di kelas? }\end{array}$ & $\begin{array}{l}\text { memperjelas penyajian materi } \\
\text { agar dapat dipahami oleh siswa } \\
\text { sehingga tidak abstrak }\end{array}$ & \\
\hline 6. & $\begin{array}{l}\text { Seperti apakah harusnya media } \\
\text { pembelajaran itu? }\end{array}$ & $\begin{array}{l}\text { dengan kesederhanaan, } \\
\text { keterpaduan, penekanan dan } \\
\text { keseimbangan }\end{array}$ & $100 \%$ \\
\hline 7. & $\begin{array}{l}\text { Sudah pernahkah guru } \\
\text { membuat/memanfaatkan media yang } \\
\text { dapat mengukur penguasaan konsep } \\
\text { siswa? }\end{array}$ & sudah pernah & $100 \%$ \\
\hline \multirow{2}{*}{8.} & \multirow{2}{*}{$\begin{array}{l}\text { Bagaimanakah pola pemanfaatan } \\
\text { media di dalam pembelajaran? }\end{array}$} & dilakukan berkelompok & $50 \%$ \\
\hline & & didemonstrasikan oleh guru & $50 \%$ \\
\hline \multirow[t]{2}{*}{9.} & \multirow[t]{2}{*}{$\begin{array}{l}\text { Sejauh mana guru melibatkan siswa } \\
\text { dalam pembelajaran menggunakan } \\
\text { media? }\end{array}$} & $\begin{array}{l}\text { terlibat dalam perencanaan, } \\
\text { pembuatan dan pelaksanaan } \\
\text { pembelajaran }\end{array}$ & $50 \%$ \\
\hline & & terlibat dalam pembelajaran saja & $50 \%$ \\
\hline \multirow[t]{2}{*}{10} & \multirow{2}{*}{$\begin{array}{l}\text { Apa saja hambatan yang guru hadapi } \\
\text { dalam memanfaatkan media untuk } \\
\text { pembelajaran? }\end{array}$} & $\begin{array}{l}\text { tidak mengalami hambatan } \\
\text { sama sekali }\end{array}$ & $75 \%$ \\
\hline & & terhambat ketersediaan dana & $25 \%$ \\
\hline
\end{tabular}

Berdasarkan hasil wawancara, dapat disimpulkan bahwa media pembelajaran sangat dibutuhkan pada tingkat sekolah dasar. Peran media dalam pembelajaran sangat penting untuk memperjelas penyajian materi agar dapat dipahami oleh siswa dan agar pembelajaran dapat berjalan dengan efektif dan efisien karena dengan adanya media pembelajaran siswa menjadi aktif dan suasana kelas tidak menjadi pasif sehingga tujuan pembelajaran bisa tercapai. Media pembelajaran dapat meningkatkan dan mengarahkan perhatian anak sehingga dapat menimbulkan motivasi belajar, interaksi yang lebih langsung antara siswa dan lingkungannya, dan kemungkinan siswa untuk belajar sendiri-sendiri sesuai dengan kemampuan dan minatnya (Arsyad, 2013). Hasil Angket validasi materi pada media pembelajaran berbentuk permainan ular tangga berbasis penguasaan konsep siswa dapat dilihat pada Tabel 2.

Tabel 2. Hasil Validasi Materi pada Media Pembelajaran

\begin{tabular}{lllll}
\hline No. & \multicolumn{1}{c}{ Indikator } & \multicolumn{3}{c}{ Jawaban } \\
\cline { 3 - 6 } & & \multicolumn{2}{c}{ Sebelum diperbaiki } & \multicolumn{2}{c}{ Sesudah diperbaiki } \\
\hline 1. & $\begin{array}{l}\text { Kesesuaian materi dengan } \\
\text { karakteristik siswa kelas } \\
\text { IV }\end{array}$ & $\begin{array}{l}\text { Materi sudah sesuai dengan } \\
\text { karakteristik siswa kelas IV }\end{array}$ & $\begin{array}{l}\text { Materi sudah sesuai } \\
\text { dengan } \\
\text { siswa kelas IV }\end{array}$ \\
\hline $\begin{array}{l}\text { 2. } \\
\text { Pengemasan materi dalam } \\
\text { media } \\
\text { dikembangkan }\end{array}$ yang & $\begin{array}{l}\text { Sangat menarik dan mampu } \\
\text { menstimulasi HOTS siswa }\end{array}$ & $\begin{array}{l}\text { Sangat menarik dan } \\
\text { mampu menstimulasi }\end{array}$ \\
\hline 3. & Kemudahan siswa dalam & Materi cukup mudah & Materi cukup mudah \\
\hline
\end{tabular}


19aribiban

\begin{tabular}{|c|c|c|c|}
\hline \multirow[t]{2}{*}{ No. } & \multirow[t]{2}{*}{ Indikator } & \multicolumn{2}{|c|}{ Jawaban } \\
\hline & & Sebelum diperbaiki & Sesudah diperbaiki \\
\hline & memahami materi & dipahami siswa & dipahami siswa \\
\hline 4. & $\begin{array}{l}\text { Kekurangan materi IPA } \\
\text { dalam media yang } \\
\text { dikembangkan }\end{array}$ & $\begin{array}{l}\text { Bahasa pada soal di media } \\
\text { masih sulit dipahami }\end{array}$ & $\begin{array}{l}\text { Bahasa pada soal di } \\
\text { media sudah lebih } \\
\text { mudah dipahami }\end{array}$ \\
\hline 5. & $\begin{array}{l}\text { Materi } \quad \text { kontekstual } \\
\text { dengan keseharian siswa }\end{array}$ & $\begin{array}{l}\text { Masih terdapat beberapa } \\
\text { materi yang tidak kontekstual } \\
\text { dengan keseharian siswa }\end{array}$ & $\begin{array}{lr}\text { Seluruh materi sudah } \\
\text { kontekstual dengan } \\
\text { keseharian siswa }\end{array}$ \\
\hline 6. & $\begin{array}{l}\text { Tingkat kebermaknaan } \\
\text { materi pada media yang } \\
\text { dikembangkan }\end{array}$ & $\begin{array}{l}\text { Sudah cukup bermakna bagi } \\
\text { siswa }\end{array}$ & $\begin{array}{l}\text { Sudah cukup bermakna } \\
\text { bagi siswa }\end{array}$ \\
\hline
\end{tabular}

Selain validasi materi pada media pembelajaran ular tangga berbasis penguasaan konsep, validasi juga dilakukan terhadap kelayakan media yang dikembangkan dalam pembelajaran di kelas. Hasil validasi angket kelayakan (validasi) media pembelajaran berbentuk permainan ular tangga berbasis penguasaan konsep dapat dilihat pada Tabel 3.

Tabel 3. Hasil Validasi Media Pembelajaran

\begin{tabular}{|c|c|c|c|}
\hline \multirow[t]{2}{*}{ No. } & \multirow[t]{2}{*}{ Indikator } & \multicolumn{2}{|c|}{ Jawaban } \\
\hline & & Sebelum Diperbaiki & Setelah Diperbaiki \\
\hline 1. & $\begin{array}{l}\text { Kemudahan } \\
\text { penggunaan media }\end{array}$ & $\begin{array}{l}\text { Media yang dikembangkan } \\
\text { cukup mudah digunakan }\end{array}$ & $\begin{array}{l}\text { Media yang dikembangkan } \\
\text { cukup mudah digunakan }\end{array}$ \\
\hline 2. & $\begin{array}{l}\text { Ketertarikan media } \\
\text { dalam } \\
\text { pembelajaran }\end{array}$ & $\begin{array}{l}\text { Media yang dikembangkan } \\
\text { cudah menarik bagi siswa }\end{array}$ & $\begin{array}{l}\text { Media yang dikembangkan } \\
\text { cudah menarik bagi siswa }\end{array}$ \\
\hline 3. & $\begin{array}{l}\text { Kemudahan } \\
\text { memahami materi }\end{array}$ & $\begin{array}{l}\text { Media yang dikembangkan } \\
\text { memudahkan siswa dalam } \\
\text { memahami materi karena sarat } \\
\text { dengan latihan-latihan soal }\end{array}$ & $\begin{array}{l}\text { Media yang dikembangkan } \\
\text { memudahkan siswa dalam } \\
\text { memahami materi karena } \\
\text { sarat dengan latihan-latihan } \\
\text { soal }\end{array}$ \\
\hline 4. & $\begin{array}{lr}\text { Kejelasan } & \text { aturan } \\
\text { dan tata } & \text { tertib } \\
\text { permainan } & \text { pada } \\
\text { media } & \end{array}$ & $\begin{array}{l}\text { Belum terdapat petunjuk yang } \\
\text { jelas dalam media yang } \\
\text { dikembangkan }\end{array}$ & $\begin{array}{l}\text { Petunjuk sudah ada dan } \\
\text { jelas }\end{array}$ \\
\hline 5. & $\begin{array}{l}\text { Kemungkinan } \\
\text { antusiasme siswa } \\
\text { pada media yang } \\
\text { dikembangkan }\end{array}$ & $\begin{array}{l}\text { Siswa pasti akan antusias dan } \\
\text { bersemangat dalam } \\
\text { melaksanakan pembelajaran } \\
\text { menggunakan media ini }\end{array}$ & $\begin{array}{l}\text { Siswa pasti akan antusias } \\
\text { dan bersemangat dalam } \\
\text { melaksanakan pembelajaran } \\
\text { menggunakan media ini }\end{array}$ \\
\hline 6. & $\begin{array}{l}\text { Kemenarikan dalam } \\
\text { kombinasi warna } \\
\text { pada media }\end{array}$ & $\begin{array}{l}\text { Warna belum menarik } \\
\text { perhatian dan masih banyak } \\
\text { kotak yang kosong, sebaiknya } \\
\text { kotak-kotak kosong diisi } \\
\text { dengan gambargambar yang } \\
\text { berkaitan dengan sumber- } \\
\text { sumber energi }\end{array}$ & $\begin{array}{l}\text { Warna media sudah sangat } \\
\text { menarik perhatian dan } \\
\text { kotak-kotak kosong telah } \\
\text { terisi dengan gambar- } \\
\text { gambar yang terkait dengan } \\
\text { materi sumber energi }\end{array}$ \\
\hline 7. & $\begin{array}{l}\text { Kesesuaian huruf } \\
\text { pada media }\end{array}$ & $\begin{array}{l}\text { Sebaiknya variasi } \\
\text { maksimal } 3 \text { jenis saja }\end{array}$ & $\begin{array}{l}\text { Variasi huruf sudah sesuai } \\
\text { dan menarik }\end{array}$ \\
\hline
\end{tabular}




\begin{tabular}{|c|c|c|c|}
\hline \multirow[t]{2}{*}{ No. } & \multirow[t]{2}{*}{ Indikator } & \multicolumn{2}{|c|}{ Jawaban } \\
\hline & & Sebelum Diperbaiki & Setelah Diperbaiki \\
\hline 8. & $\begin{array}{l}\text { Daya tarik desain } \\
\text { pada media yang } \\
\text { dikembangkan }\end{array}$ & $\begin{array}{l}\text { Memiliki daya tarik pada } \\
\text { permainan dan kesempatan } \\
\text { yang sama pada setiap siswa } \\
\text { dalam menjawab pertanyaan }\end{array}$ & $\begin{array}{l}\text { Memiliki daya tarik pada } \\
\text { permainan dan kesempatan } \\
\text { yang sama pada setiap siswa } \\
\text { dalam menjawab pertanyaan }\end{array}$ \\
\hline
\end{tabular}

Setelah melalui tahap desain, pengembangan, dan validasi, maka didapatlah media pembelajaran berbentuk permainan ular tangga yang layak (valid) baik secara isi materi maupun kemenarikan dan kemudahan penggunaan media dalam pembelajaran IPA di sekolah khususnya pada materi sumber energi. Desain media pembelajaran berbentuk permainan ular tangga berbasis penguasaan konsep yang telah valid dapat dilihat pada Gambar 1.

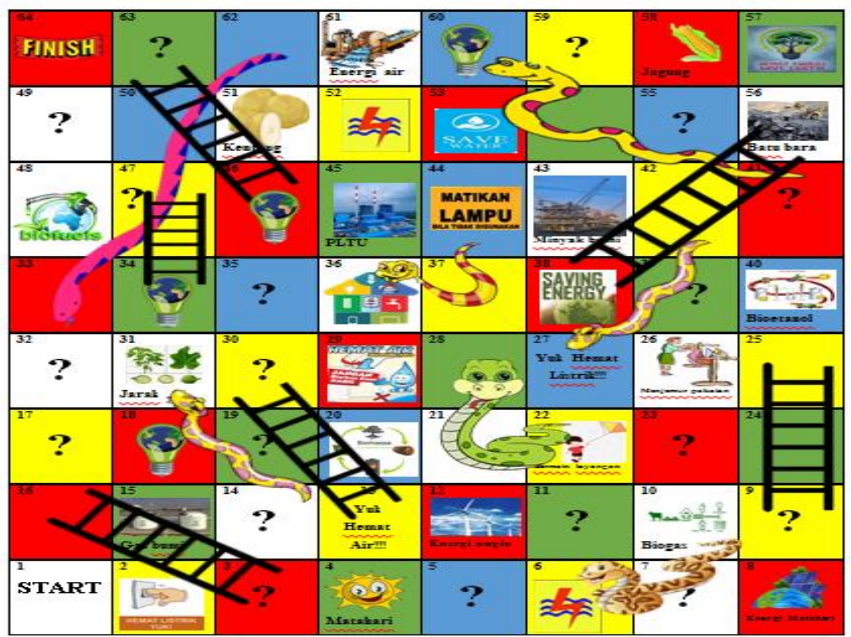

Gambar 1. Desain Media Pmbelajaran Ular Tangga Berbasis Penguasaan Konsep

\section{Simpulan}

Berdasarkan hasil validasi yang dilakukan oleh validator media pembelajaran dapat disimpulkan bahwa desain media pembelajaran ular tangga berbasis penguasaan konsep pada materi sumber energi yang dikembangkan sudah baik, menarik, valid dan layak. Tahap selanjutnya dapat dilakukan uji coba terbatas dalam pembelajaran di sekolah dasar.

Dalam penelitian ini penulis hanya melakukan pengembangan pada tahap analisis masalah, desain media pembelajaran dan pengembangan media pembelajaran dengan validasi oleh validator. Untuk selanjutnya dapat dilaksanakan penelitian lanjutan pada tahap implementasi (praktik terbatas) dan evaluasi pelaksanaan untuk pembelajaran menggunakan media pembelajaran berbentuk permainan ular tangga berbasis penguasaan konsep 
untuk melihat dan memperbaiki kekurangan media yang telah dibuat secara nyata.

\section{Daftar Pustaka}

Affandi. (2015). Pegembangan Media Pembelajaran Permainan Ular Tangga Untuk Meningkatkan Motivasi Belajar Siswa dan Hasil Belajar IPS di Sekolah Dasar. Jurnal Inovasi Pembelajaran 1(1), 77-79.

Arianti, Shaidu, Harjono \& Gunawan. (2016). Pengaruh Model Direct Intruction Berbantuan Simulasi Virtual Terhadap Penguasaan Konsep Siswa. Jurnal Pendidikan Fisika dan Teknologi 2(4), 83-84.

Arisanti, Sopanti \& Widodo. (2016). Analisis Penguasaan Konsep dan Keterampilan Berpikir Kreatif Siswa SD Melalui Project Based Learning. Jurnal Pendidikan Dasar 8(1), 86-87.

Astuti. (2017). Penguasaan Konsep IPA Ditinjau dari Konsep Diri dan Minat Belajar Siswa. Jurnal Formatif 7(1), 42-43.

Ferryka. (2017). Permainan Ular Tangga Dalam Pembelajaran Matematika di Sekolah Dasar. Jurnal Magistra 29(100), 61-62.

Fatimah, Gunawan \& Wahyudi. (2016). Pembelajaran Berbasis Masalah Dengan Strategi Konflik Kognitif Terhadap Penguasaan Konsep dan Kemampuan Berpikir Kritis Fisika Siswa Kelas XI SMKN 1 Lingsar Tahun Pelajaran 2015/2016. Jurnal Pendidikan Fisika dan Teknologi, 2(4), 186.

Kurniawan, Tresnawati, \& Maryanti. (2018). Peran Matakuliah Konsep Dasar Ilmu Pengetahuan Alam Dalam Membekali Kompetensi Calon Guru Sekolah Dasar. Jurnal Ilmiah Ilmu Pendidikan Dasar, 1(1), 62-63.

Karimah, Supurwoko \& Wahyuningsih. (2014). Pengembangan Media Pembelajaran Ular Tangga Fisika Untuk Siswa SMP/Mts Kelas VII. Jurnal Pendidikan Fisika, 2(1), 7-8.

Kusumawati. (2017). Pengaruh Permainan Tradisional Terhadap Peningkatan Kemampuan Gerak Dasar Siswa Sekolah dasar Kelas Bawah. Jurnal Pendidikan dan Pembelajaran Dasar, 4(2), 93-131.

Nur, Mulyana \& Perdana. (2017). Permainan Bola Kecil Untuk Meningkatkan Keterampilan Motorik Kasar Anak Usia Dini Pada Kelompok B di TK Pertiwi DWP Kota Tasikmalaya. Jurnal Paud Agapedia, 1(1), 59-60.

Ninik. (2018). Monitoring Pembelajaran Konsep Learning BY Playing And Playing For Learning Sebagai Peningkatan kualitas Pendidikan di TK. Jurnal PINUS 3(2), 109-119.

Purwono, Yutmini \& Anitah. (2014). Penggunaan Media Audio-Visual Pada Mata Pelajaran Ilmu Pengetahuan Alam Di Sekolah Menengah Pertama 1 Pacitan. Jurnal Teknologi Pendidikan dan Pembelajaran 2(2), 129-130.

Purwanti. (2015). Pengembangan Media Video Pembelajaran Matematika dengan Model Assure. Jurnal Kebijakan dan Pengembangan Pendidikan 3(1), 43-44.

Rasyid \& Rohani. (2018). Manfaat Media dalam Pembelajaran. AXIOM 7(1), 12-15.

Salam, Safei \& Jamilah. (2019). Pengembangan Media Pembelajaran Permainan Ular Tangga Pada Materi Sistem Saraf. Jurnal Al-Ahya 1(1), 54-55.

Setiawati, Destri \& Solihatulmiah. (2019). Permainan Ular Tangga Dalam Meningkatkan Kemampuan Moral Anak. Jurnal PETIK 5(1), 1-10.

Suprapto. (2013). Permainan Monopoli Sebagai Media Untuk Meningkatkan Minat Belajar Tata Boga di SMA. Jurnal Ilmiah Guru 1(1), 1-10.

Sugiyono. 2014. Metode Penelitian Kuantitatif, Kualitatif dan R\&D. Aflabeta. Bandung.

Tyaningsih, Haryono \& Nurhayati. (2012). Penerapan Model Pembelajaran TGT (Teams Games Tournament) Diilengkapi LKS Untuk Meningkatkan Aktivitas Dan Hasil Belajar 
Materi Minyak Bumi Pada Siswa Kelas X-4 SMA Batik 1 Surakarta Tahun Pelajaran 2011/2012. JPK 1(1), $26-27$.

Tafonao. (2018). Peranan Media Pembalajaran Dalam Meningkatkan Minat Belajar Mahasiswa. Jurnal Komunikasi Pendidikan 2(2), 103. 